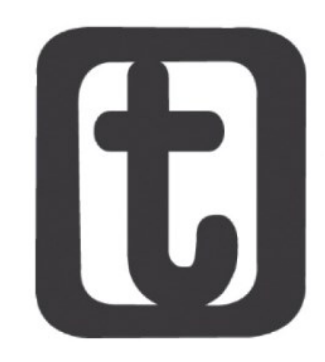

\title{
“ENTRE AMORES E DISSABORES”: A POLÍTICA DE ASSISTÊNCIA SOCIAL VOLTADA AOS/ÀS LGBTS
}

\author{
"Between lovers and dissaborms": the social assistance policy to LGBT \\ Kaline de Souza Barbosa* \\ Poliana Machado Gomes da Silva** \\ Jéssyka Kaline Augusto Ribeiro***
}

\begin{abstract}
RESUMO
Este artigo tece análises sobre os avanços e os desafios da Política de Assistência Social no que tange ao atendimento da população de lésbicas, gays, bissexuais, travestis, transexuais e transgêneros (LGBT). Objetiva-se, portanto, investigar os (des)caminhos da Política de Assistência Social voltada a este público. À vista disso, este artigo parte de uma pesquisa de natureza qualitativa, subsidiada por um levantamento bibliográfico e análise documental acerca do objeto de estudo. Logrou-se como principais resultados que, apesar das conquistas da Política de Assistência Social, a mesma não elucida a população LGBT enquanto seus/suas usuários/as. Esse seguimento só adentra na política por meio das categorias vulnerabilidade e risco social, ambas indicadoras de fragilidade na delimitação dos/as seus usuários/as. Por fim, não se encontram os termos identidade de gênero e orientação sexual nas legislações da Política de Assistência Social, como também não se incorpora as famílias formadas pela população LGBT.
\end{abstract}

\section{PALAVRAS-CHAVE}

LGBT. Política de Assistência Social. Sexualidade. Direitos.

\section{ABSTRACT}

This article analyzes the advances and challenges of the Social Assistance Policy regarding the care of the lesbian, gay, bisexual, transvestite, transsexual and transgender (LGBT) population. The objective is, therefore, to investigate the (dis)ways of the Social Assistance Policy aimed at this public. In view of this, this article starts from a qualitative research, subsidized by a bibliographical survey and documentary analysis about the object of study. It was achieved as main results that despite the achievements of the Social Assistance Policy, as a result of its theoretical and operational maturation, it did not elucidate the LGBT population as its users. This follow-up only enters into the Social Assistance Policy through the vulnerability and social risk categories, both indicative of fragility in the delimitation of its users. In addition, and finally,

\footnotetext{
* Assistente Social. Especialista em direito de familias pela Universidade Regional do Cariri (URCA, Crato, Brasil). Rua Coronel Antônio Luíz, 1161 - Pimenta, Crato (CE), CEP.: 63105-010. ORC ID: <https://orcid.org/00oo0002-8762-7951>. E-mail:<k-alyne@hotmail.com>.

${ }^{* *}$ Assistente Social. Mestranda em Serviço Social, Trabalho e Questão Social pela (UECE, Fortaleza, Brasil). Av. Dr. Silas Munguba, 1700 - Campus do Itaperi, Fortaleza - CE, 60741-000 ORC ID: < https://orcid.org/0000-00018220-6229>. E-mail: <polly.mach@hotmail.com>.

${ }^{* * *}$ Assistente Social. Doutoranda em Serviço Social Pela Universidade Estadual do Rio de Janeiro (Uerj, Rio de Janeiro, Brasil). Rua São Francisco Xavier, 524, Maracanã, Rio de Janeiro - RJ - Cep 20550-900. E-mail: <jsk.ribeiroz@gmail.com>.
}

DOI 10.22422/temporalis.2018v18n36p239-255 
the terms gender identity and sexual orientation in the legislation of the Social Assistance Policy are not found, nor is it incorporated in its text the families formed by the LGBT population.

\section{KEY WORDS}

LGBT. Social Assistance Policy. Sexuality. Rights.

Submetido em: 30/9/2018.

Revisado em: 21/11/2018.

Aceito em: 23/11/2018.

\section{INTRODUÇÃO}

A Política de Assistência Social no Brasil possui como objetivo atender indivíduos em situação de vulnerabilidade e risco social. É através de tais categorias que se pode considerar que os/as lésbicas, gays, bissexuais, travestis, transexuais e transgêneros (LGBT) se consolidam enquanto usuários/as da política em questão. Nada obstante, tais categorias (vulnerabilidade e risco social) funcionam, conforme Mota et al. (2010), como indicadores de exclusão ${ }^{1}$, inerentes de fragilidades dos próprios serviços a serem prestados nos níveis de proteção social propostos.

No que tange à redação da Política Nacional de Assistência Social (PNAS), existem impasses no que concerne à efetivação de diretos da população LGBT $^{2}$. À guisa de exemplo, tem-se o subtítulo "Família e Indivíduos [...]" (BRASIL, 2004, p. 20), o qual destaca que o conceito de família passa por transformações, entretanto, refere-se somente às mulheres que chefiam núcleos familiares. Excluem-se, assim, as famílias formadas por casais de pessoas do mesmo gênero, com ou sem filhos/as, biológicos/as ou adotivos/as, além de serem suprimidas as famílias monoparentais, onde a/o mãe/pai é LGBT. A PNAS ainda referencia a categoria gênero relacionada apenas às mulheres, dificultando a possibilidade de reconhecimento das configurações de conjugalidade e parentalidade de LGBTs, como também não são mencionados os termos orientação sexual e identidade de gênero.

Há de se convir que constitui condição sine qua non o debate sobre o atendimento da PNAS destinado à população LGBT, uma vez que o Brasil apresenta o maior índice de mortalidade LGBTs do mundo. De acordo com o relatório de mortes violentas de LGBT no Brasil, "a cada 19 horas um LGBT é barbaramente assassinado ou se suicida vítima da "LGBTfobia"

\footnotetext{
1 Estes indicadores não anunciam a existência de uma nova questão social, posto que seus pilares fundamentais não foram superados. Quais sejam: o antagonismo da relação capital e trabalho, a propriedade privada dos meios de produção e a produção coletiva, a produção de riquezas na mesma proporção em que se produz a miséria, a exploração e a dominação, bem como os confrontos de classe. Assim, o que ocorre de fato é o redimensionamento de conflitos e determinações no seio da ordem comanda pela subsunção do trabalho ao capital (MOTA et al., 2010). Logo, em antagonismo às teses que advogam a existência de uma nova questão social, assevera-se aqui a existência de manifestações da questão social, como a LGBTfobia.

${ }^{2} \mathrm{Em} 2008 \mathrm{com}$ a $1^{\circ}$ Conferência Nacional de Gays, Lésbicas, Bissexuais, Travestis e Transexuais foi padronizado a nomenclatura do movimento homossexual brasileiro que até então usava a sigla GLBT, passaria a usar LGBT - Lésbicas, Gays, Bissexuais, Travestis e Transexuais - a mudança de posição da letra se dá ao fato de uma maior visibilidade para as reivindicações das mulheres lésbicas (FACCHINI, 2005). Entretanto, existem outras nomenclaturas para designar tal grupo como: LGBTQ (lésbicas, gays, bissexuais, transexuais, travestis, transgêneros, queer), LGBTQI (lésbicas, gays, bissexuais, transexuais, travestis, transgêneros, queer, intersexuais), LGBTI+ ( lésbicas, gays, bissexuais, transexuais, travestis, transgêneros, intersexuais), e LGBTQQICAPF2K+ (Lésbicas, Gays, Bisexuais, Transexuais, Queer, Questionando-se, Interssexuais, Asexuados, Sem Gênero, Simpatizante, Curiosos, Panssexuais, Polissexuais, Amigos e Familiares, "Dois-espíritos", Kink). Todavia, será utilizado neste artigo o termo LGBT, devido ser a sigla utilizada nos documentos oficiais das conferências e por autores/as citados/as no decorrer do texto.
} 
(GRUPO GAY DA BAHIA, 2017, p.1), o que faz do Brasil o campeão mundial de crimes contra os/as LGBTs. Tais dados confirmam que a violência sofrida pelos/as mesmos/as, uma vez que os mecanismos regulatórios capitalistas excluem e oprimem tal comunidade, explorando-a, marginalizando-a, violentando-a e mercantilizando-a.

À vista disso, esta pesquisa objetiva investigar os (des)caminhos da Política de Assistência Social voltada à população LGBT. Para tanto, este artigo parte de uma pesquisa de natureza qualitativa, subsidiada por um levantamento bibliográfico tendo como fontes principais os escritos de Foucault (1980), Scott (1990), Butler (2013), e Luiz Mello et al (2013). O trabalho conta ainda com análises documentais, tais como os relatórios da Conferências LGBT e de Assistência social e os escritos legislativos da PNAS.

\section{AS RELAÇÕES DE PODER IMBRICADAS NA CONSTRUÇÃO DAS IDENTIDADES E DA SEXUALIDADE}

Para autores Scott (1990) e Butler (2013), o gênero se torna uma maneira de indicar as construções sociais: a criação inteiramente social das ideias sobre os papéis próprios aos homens e às mulheres. Logo, o gênero pode abarcar o sexo, mas não é diretamente determinado por ele - e nem o determina. Assim, formas diversas de feminilidades e masculinidades se constituem nas relações sociais. Entendendo que os atravessamentos que constituem cada ser humano são únicos e singulares, a identidade de gênero - maneira como cada um se apresenta socialmente de acordo com o gênero constituído é a convicção íntima de uma pessoa.

À vista disso, identidade de gênero e orientação sexual não apresentam uma mesma significação. A primeira se refere a como o indivíduo se reconhece (homem, mulher, trans); a segunda diz respeito à capacidade de cada pessoa de ter uma profunda atração emocional, afetiva e/ou sexual por indivíduos de gênero diferente, do mesmo gênero ou de mais de um gênero, assim como ter relações íntimas e sexuais com essas pessoas.

Nesse sentido, este trabalho comunga da concepção de gênero de Joan Scott (1990). Isto porque, acredita-se que o gênero é uma percepção sobre as diferenças sexuais que se encontram hierarquizadas no interior de uma maneira de pensar engessada e dual, isto é, binária. Sendo assim, a identidade de gênero não partiria de uma predisposição biológica, mas traz em si um conjunto de elementos que devem ser pensados, refletidos e ressignificados.

Ademais, observa-se no transcorrer da história da sexualidade que a mesma está intrinsecamente envolvida nas relações de poder na sociedade ocidental, na qual o ser mulher e o ser homem caracterizam papeis fundamentais no contexto societário. Dada esta lógica, verifica-se um caráter subserviente do primeiro (ser mulher) ao segundo (ser homem). A dicotomia entre masculino e feminino, entre macho e fêmea acabou por atribuir funções sociais que subsumiram as mulheres aos homens. 
Michel Foucault (1988), ao falar sobre o $\operatorname{poder}^{3}$ que atravessa o campo da sexualidade (biopoder) relata que uma destas primeiras formas de poder (ainda existente) é o chamado dispositivo da aliança. Este dispositivo era e é instituído na sociedade através das religiosidades, por meio do matrimônio (entre o homem e a mulher), do monogamismo (nas sociedades ocidentais). Em contraponto ao dispositivo da aliança tem-se o dispositivo da sexualidade, ambos tratam de parcerias sexuais, porém com vieses diferentes. Enquanto o dispositivo da aliança se estabelece entre o proibido e o não proibido, entendendo o sexo como de natureza puramente reprodutiva, o dispositivo da sexualidade não o compreende dessa forma. O sexo é, pelo dispositivo da aliança, entendido como a exploração do corpo e o seu controle. Assim, o dispositivo da aliança tende a perpetuar um conjunto de regras que lhe é próprio, enquanto que o da sexualidade é flexível às relações de poder existentes (FOUCAULT, 1988).

As relações de gênero são circunscritas no interior da sociedade, e trazem ideologias de instituições que são caracterizadas por Foucault (1997) como fazendo parte de uma rede de micro poderes, legitimada não somente pela sociedade, mas também pelo Estado. As relações de gênero se comportam como relações de poder uma vez que se encontram numa ideologia de dominador e dominado, de hierarquização dos sexos.

A sexualidade é perpassada por aqueles esquemas de classificação, fundados na oposição e hierarquização entre masculino/feminino, a partir da oposição entre ativo/passivo, o que estabelece uma ligação entre sexualidade e dominação: as imagens, o vocabulário e as significações mobilizadas em cada sociedade para evocar as relações sexuais são, em todos os lugares, utilizados para dizer igualmente a dominação de sexo em geral (BOZON, 1999 apud ANJOS, 2000, p. 275).

Logo, nesta relação de poder a partir das diferenças sexuais coloca em evidência a valorização de um sexo sobre outro, onde o que é masculino é sempre bem visto, valorizado e superestimado, enquanto aquilo que culturalmente é próprio do sexo feminino é inferiorizado, subordinado ao masculino. Nesse sentido, tanto as representações de gênero quanto as relações de gênero são construídas culturalmente e socialmente através das diferenças sexuais e/ou a partir do determinismo biológico, impondo um modelo padrão de como o homem e a mulher devem se comportar tanto socialmente quanto no expressar da sua sexualidade.

O padrão do determinismo biológico, encontrado nas sociedades ocidentais, impõe e perpetua a concepção de heteronormatividade. Esta estabelece como sendo normal/natural e legítimo apenas as relações heterossexuais, ou seja, entre pessoas de sexo biológico opostos. Logo, qualquer outra forma de relacionamento que não siga a este discurso é considerada sadomia, pela qual os sujeitos são compreendidos como pecadores, e/ou desviantes e monstruosos. Nesse sentido,

\footnotetext{
${ }^{3}$ Foucault (1988), entende o poder como correlações de forças imanentes ao domínio onde se exercem e constitutivas de sua organização; forças que encontram apoio entre si, formando cadeias ou contradições e consolidam-se nos aparelhos do Estado, e nas leis. Essas forças induzem continuamente estados de poder, sempre localizados e instáveis. Pode-se dizer que o poder está em toda parte, se produzindo a cada instante em todas as relações.
} 
Os discursos normativos de gênero produzem a inteligibilidade/ininteligibilidade e a normalidade/anormalidade dos corpos e dos sujeitos, a partir de padrões estabelecidos culturalmente, os quais só persistem como normas, á medida que 'se realizam na prática social e se idealizam novamente e se reinstituem em e por meio dos rituais diários da vida e do corpo' (BUTLER, 2006 apud PARAISO, 2014, p. 239-240).

O discurso heteronormativo está presente na vida dos sujeitos desde o período gestacional/nascimento, através da dicotomia dos sexos, onde se é ensinado aos indivíduos a se comportarem de acordo com tais padrões (heteronormativos). Perpetuase, assim, que quando crianças, meninos (que tem pênis) brinquem com carrinhos e usam roupas azul; e meninas (que tem vagina) brinquem com bonecas e usam roupas rosa. Todavia, vale ressaltar que esta relação do que é masculino e do que é feminino pode sofrer mutações com o tempo como bem coloca Sardenberg (2011): que o que em um período era tido como essencialmente masculino pode também ser incorporado ao que é essencialmente feminino em outra época.

Todavia, a homossexualidade subverteria a norma, a partir da ocupação, no caso da homossexualidade masculina, de uma posição inferior (dominada) que foi construída historicamente pelas instituições médicas a partir da concepção da prática homossexual como enfermidade, e não mais como pecado. Já no caso da homossexualidade feminina, haveria a possibilidade de subversão de uma posição de subordinação, a partir da negação do papel atribuído à mulher: subordinar-se, também sexualmente, ao homem. Aos sujeitos que fogem a estas ditas regras sociais Ihes cabem os títulos de anormais, ininteligíveis.

Os 'gêneros inteligíveis', que funcionam predominantemente ainda hoje, se organizam segundo a lógica do 'tem pênis, logo é homem, masculino e deve sentir atração afetivo-sexual por mulheres (é heterossexual)', e 'tem vagina, logo é mulher, feminina e deve sentir atração afetivo sexual por homens'. Nesse campo, tanto pessoas homossexuais, bissexuais, quanto intersexuais, travestis, transexuais e todas aquelas que quebram essa pressuposta continuidade podem ser consideradas abjetas (LEITE JUNIOR, 2012, p. 561).

Nesse ínterim, atribui-se à sexualidade dos indivíduos a função de confirmação de suas identidades de gênero (só aceitas como masculinas ou femininas), definidas pelo seu pertencimento biológico a um dos sexos (macho ou fêmea). Essa cadeia de coerências identitárias se configura como norma que torna inconcebível outra forma de se viver as identidades sexuais e de gênero fora dos relacionamentos heterossexuais. A esse processo de normatização, dá-se o nome de heteronormatividade ${ }^{4}$. Esta última diz respeito à norma que rege a vivência da sexualidade tanto para homens quanto para mulheres. Todavia esse termo não deve ser analisado separadamente do conceito de cisgeneridade (quando o gênero apresenta identidade com o sexo biológico) (BALESTRIN, 2006).

Dessa forma, cabe refletir: $O$ que ocorre com aqueles/as aquelas que se desviam do padrão heteronormativo? Quando essas pessoas desviantes sofrem violência, a quais instituições devem recorrer? É certo que os/as LGBTs, desviantes da heteronormatividade compulsória,

\footnotetext{
${ }^{4}$ Pela lógica impositiva da heteronormatividade, todas as pessoas devem ser heterossexuais e todos os bens produzidos pela sociedade, sejam eles materiais ou simbólicos, são destinados para quem vive segundo seus preceitos.
} 
ganharam e vem ganhando mais visibilidade no cenário político. No entanto, não houveram avanços legislativos eficazes em relação ao combate à violência sofrida por eles/elas, nem tampouco são citados/as nos documentos reguladores das políticas sociais, em especial da Política de Assistência Social, objeto de estudo do próximo tópico.

\section{BREVES APONTAMENTOS SOBRE A POLÍTICA DE ASSISTÊNCIA SOCIAL NO BRASIL}

No Brasil, a PNAS não era compreendida enquanto uma política social e de direito do/a cidadão/ã até a Constituição Federal de 1988 (BRASIL, 1988). Pelo contrário, a Assistência Social em sua gênese se encontra em meio ao assistencialismo, à benemerência, e à filantropia praticados pelas damas da burguesia e/ou entidades religiosas de amparo e caridade aos/às pobres e necessitados/as.

Com a Constituição Federal de 1988, em seus artigos 203 e 204, a Assistência Social passa a constituir o tripé da Seguridade Social juntamente com a saúde e a previdência social, sendo reconhecida enquanto política pública não contributiva. Ademais, passa a ser ofertada a quem dela necessitar, constituindo-se como um direito do/a cidadão/ã e dever do Estado. Tempos depois, em 1993, foi promulgada a Lei Orgânica da Assistência Social (LOAS) Lei $\mathrm{n}^{\circ}$ 8.742, trazendo um caráter de maturidade legal para os serviços socioassistenciais. A LOAS dispõe sobre os objetivos e princípios da Política de Assistência Social, preconizando, a Lei $\mathrm{n}^{\circ} 8.742 / 93$ ainda institui o Conselho Nacional de Assistência Social (CNAS). Tal conselho não possui uma intervenção exclusiva do governo, mas conta com a intervenção da sociedade civil, atuando em diferentes níveis, tanto para a formulação e implementação (da PNAS) quanto para gestão do próprio Conselho, tendo em vista, a viabilização no uso de transferência e redistribuição (da PNAS).

Pode-se constatar certos avanços na Política de Assistência Social brasileira nos últimos anos, sobretudo no que se refere ao seu cariz conceitual e operacional. Estes evidenciam uma construção teórica de um modelo pautado na lógica da garantia de direitos. Todavia, não podemos deixar de ressaltar o impacto que teve a política neoliberal que foi implantada no contexto brasileiro na década de 1990.

Atualmente, a sociedade do capital vivencia um fenômeno designado mundialização que visa adesão ao projeto neoliberal (iniciado com a queda/crise do walfare state). Isto corrobora para o superdimensionamento antagônico da relação entre capital e trabalho, o que conduz à intensificação dos processos de precarização, sucateamento, privatização, focalização e descentralização das políticas públicas. Logo, o neoliberalismo se expressa através do Estado máximo para o capital, consequentemente, mínimo para o social. Elucida Elaine Behring (2009) sobre as políticas sociais no contexto neoliberal: "[...] as políticas sociais entram, neste cenário caracterizadas como: paternalistas, geradoras de desequilíbrio, custo excessivo do trabalho, e, de preferência, devem ser acessadas via mercado, transformando-se em serviços privados" (BEHRING, 2009, p. 76).

A Política de Assistência Social no limiar neoliberal não foge a esta lógica. Nesse contexto, há um difícil processo de ruptura com os traços assistencialistas que ainda pairam o campo da Assistência Social. Os resquícios da cultura moralista, a qual culpabiliza o indivíduo pelas 
suas mazelas de teor econômico e social, descartam, desta maneira, que vários são os determinantes que compõem a totalidade da vida social.

No ano de 2004 através da resolução de nº 145 é aprovada a Política Nacional de Assistência Social (PNAS). Conforme Bazza e Carvalho (2013): “A atuação da PNAS visa o enfrentamento das desigualdades sócio territoriais, garantindo os mínimos sociais, para atender contingências sociais e à universalização dos direitos sociais" (BAZZA; CARVALHO, 2013, p. 31). Ou seja, busca-se promover principalmente a defesa e a atenção aos interesses e necessidades às pessoas em situação de risco e/ou vulnerabilidade social, cabendo à mesma, ações que promovam a prevenção, a proteção, a promoção e a inserção social, como também um conjunto de garantias e seguranças.

Nos anos 2000, na conjuntura sócio-histórica brasileira, o campo da assistência social teve, inicialmente, um salto no que diz respeito a sua sistematização, todavia o seu caráter focalista e seletivo ainda são predominantes. Em 2005, há a concretização do Sistema Único de Assistência Social 5 (SUAS), cuja deliberação advém da IV Conferência Nacional de Assistência Social realizada em dezembro de 2003. Isto significa que o SUAS só se concretiza num período tardio de dois anos. O SUAS consolida a PNAS, bem como organiza e estrutura as funções assistenciais no que tange à proteção social, à vigilância social e à defesa dos direitos socioassistenciais.

Sobre o SUAS, a PNAS (2004) elucida que os seus eixos estruturantes são: Matricialidade sociofamiliar; descentralização político-administrativa e territorialização; novas bases para a relação entre o Estado e a sociedade civil; o financiamento; o controle social; o desafio da participação popular/cidadãos/usuários; a política de recursos humanos; a informação, o monitoramento e a avaliação. O SUAS é um sistema público que organiza os serviços de Assistência Social no Brasil. Com um modelo de gestão participativa, ele articula os esforços e os recursos dos três níveis de governo, isto é, municípios, estados e União, para a execução e o financiamento da Política Nacional de Assistência Social (PNAS). Para tanto, envolve diretamente estruturas e marcos regulatórios nacionais, estaduais, municipais e do Distrito Federal.

A Política de Assistência Social na contemporaneidade é definida pelo seu nível de complexidade (básica, especializada: média e alta complexidade). Os Serviços de Proteção Social Básica devem ser percebidos, conforme incidem sobre famílias, indivíduos e sociedade, cujos direitos ainda não foram rompidos. Nesse sentido, possui um caráter preventivo, tendo por intuito o processo da inclusão social, no mundo do trabalho e na vida em comunidade de grupos e indivíduos em situação de vulnerabilidade social, risco social ${ }^{6}$ e pessoal. Pontua Boschetti (2005) que, na implantação da proteção social básica, " [...] é

\footnotetext{
${ }^{5}$ O SUAS é um sistema público, não contributivo, descentralizado e participativo, e tem como função administrar o conteúdo específico da Assistência Social, no campo da proteção social.

${ }^{6}$ Monteiro (2011) corrobora que a vulnerabilidade social, por ser na maioria das vezes compreendida ora adjetivada do sujeito (colocando-o como responsável pela condição de vulnerabilidade, e atuando sob uma perspectiva de culpabilização do sujeito), ora sustentada na ideia de risco e potencialidades (onde se trabalha o fortalecimento das capacidades e potencialidades do sujeito), se concentra apenas no sujeito e não na estrutura social. Logo, a interpretação de maneira isolada da vulnerabilidade social, centrada apenas no sujeito e desconecta da análise das estruturas da sociedade capitalista podem conduzir à manutenção status quo da ordem capitalista, comprometendo a garantia de direitos.
} 
um desafio do SUAS buscar articulação com a proteção social garantida pela saúde, previdência e demais políticas públicas, de modo a estabelecer programas gerais e preventivos" (BOSCHETTI, 2005, p. 13).

Em 2006 foi aprovada a Norma Operacional Básica de Recursos Humanos (NOBRH/ SUAS), através da resolução n $269 / 2006$ do CNAS. A mesma estabeleceu níveis de gestão para que os municípios obtivessem acesso aos recursos em escala federal, objetivando associar a gestão e o financiamento e, com isso, definir requisitos para cada nível de gestão, além de colocar o combate à terceirização dos/as servidores/as do SUAS. Em 2012 é aprovada a resolução $n^{\circ} 33$ do CNAS, mais conhecida como NOB/SUAS 2012, que revoga a resolução $n^{\circ}$ 130 do CNAS.

Em 2015, o SUAS completou 10 anos, apresentando um avanço considerável neste período, promoveu o acesso a benefícios à Assistência Social. O SUAS é o responsável pela criação de Centros de Referência da Assistência Social (CRAS), presentes em 5.541 municípios brasileiros, e dos Centros de Referência Especializados de Assistência Social (CREAS). Todavia, o que não se esperava era a conjuntura do ano de 2016, momento de grandes mudanças no cenário político nacional, que afeta drasticamente as políticas sociais, em especial a política de assistência social.

\section{A POLÍTICA DE ASSISTÊNCIA SOCIAL VOLTADA PARA A POPULAÇÃO LGBT NA CONTEMPORANEIDADE}

A Política de Assistência Social, ao transcorrer do tempo vem adquirindo avanços significativos tanto na esfera legislativa quanto na esfera dos serviços socioassistenciais. Nada obstante, será que a PNAS contempla todos os públicos e demandas que podem se apresentar nos seus equipamentos, em especial os/as LGBTs? Será que a PNAS através de seus aparelhos tem realizado ações voltadas para os/as LGBTs? E, por fim, será que o debate sobre sexualidade e opressão de gênero são pautas no interior da Política de Assistência social? São questões que iremos desenvolver a seguir.

Alguns programas surgiram para atender as demandas LGBTs como é o caso do Programa Brasil sem Homofobia (BSH) - proposto em 2004, por meio da Secretaria Especial de Direitos Humanos (SEDH) da Presidência da República - hoje, Secretaria de Direitos Humanos (SDH) -, no âmbito do Programa Direitos Humanos, Direitos de Todos. A proposta contida no "Brasil Sem Homofobia, Programa de Combate à Violência e à Discriminação contra GLTB ${ }^{8}$ e de Promoção da Cidadania Homossexual" (CONSELHO NACIONAL DE COMBATE À DISCRIMINAÇÃO, 2004), é “[...] promover a cidadania GLBT, a partir da equiparação de direitos e do combate à violência e à discriminação homofóbicas,

\footnotetext{
7 De acordo com a NOB/SUAS 2012, a mesma foi adotada devido a necessidade de revisão do SUAS nas categorias de habilitação dos municípios e também pelo fato de que os municípios "[...] habilitados nos níveis de gestão inicial e básica recebiam incentivos relacionados aos serviços de proteção social especial de média e alta complexidade, mas não possuíam responsabilidade, estabelecida na NOB, de estruturar a rede de referência" (BRASIL, 2012, p. 14).

${ }^{8}$ Destaca-se que durante essa conferência foi aprovado o uso da sigla LGBT para a denominação do movimento, o que se justificaria pela proposta de visibilizar o segmento das lésbicas (FACCHINI; FRANÇA, 2009).
} 
respeitando a especificidade de cada um desses grupos populacionais" (CONSELHO NACIONAL DE COMBATE À DISCRIMINAÇÃO , 2004, p. 11).

O BSH foi estruturado em um plano plurianual (PPA) de 2004/2007, sendo equacionado em princípios básicos e programas de ações articulados a uma política de direitos LGBTs. Entretanto, o mesmo não possui nenhuma ala específica para ações no campo da Política de Assistência Social, como tem nas áreas de educação, saúde, segurança, trabalho e cultura. Entretanto, dentre estes campos existem ações que também perpassam o campo da Assistência Social, tais como: a capacitação de profissionais nos mais diversos Ministérios, a criação de instrumentos técnicos para diagnosticar e avaliar a situação de violação aos direitos humanos de homossexuais e de testemunhas de crimes relacionados à orientação sexual para levantar os tipos de violação, a tipificação e o contexto dos crimes, o perfil de autores e o nível de vitimização, de modo a assegurar o encaminhamento das vítimas LGBT, em serviços de assistência e proteção.

Em 2008 foi realizada a I Conferência Nacional LGBT no Brasil, que traz eixos e ações a serem tomadas para o combate à LBGTfobia em diferentes políticas como Previdência Social, Trabalho e Renda, e Assistência Social. Pontua Luiz Mello et al. (2013):

\begin{abstract}
Nos Anais da I Conferência Nacional LGBT observa-se a desarticulação entre as propostas relativas à assistência social, uma vez que, em face da inexistência de grupo de trabalho (GT) específico sobre o tema, as 11 deliberações aprovadas estão distribuídas em diferentes GTs: 'saúde', 'educação', 'previdência social', 'trabalho e emprego' e 'cidades'. Tais propostas tratam basicamente da necessidade de capacitação de profissionais da assistência social para o atendimento à população LGBT (em abrigos e demais serviços sócio assistenciais); da inserção das categorias identidade de gênero e orientação sexual no SUAS e na PNAS; e da articulação entre a política de assistência social e as demais políticas públicas. (MELLO et al, 2013, p. 138).
\end{abstract}

A PNAS em seu documento redigido em 2004, não faz nenhuma referência à população LGBT, não faz alusão à identidade de gênero, reforçando a ideia de que gênero é colocado somente em relação às mulheres, o que dificulta a realização de ações voltadas para os/as LGBTs9 ${ }^{9}$ É a partir da proposta do BSH (que por não ter sido implantado não obteve nenhum resultado sobre a política em discussão) e mais especificadamente com a I Conferência Nacional LGBT que se irá pensar neste grupo dentro da Política de Assistência Social. Segundo Mello et al. (2013), apesar de se ter um grande avanço na discussão sobre LGBTs na Política de Assistência Social, com a I Conferência supracitada, as problematizações foram colocadas em segundo plano, apresentando poucas ações a serem operacionalizadas, não proporcionando mudanças radicais no cenário social do país.

A I Conferência Nacional LGBT, apesar de propor ações de mudanças, não conseguiu efetivar seu objetivo, tampouco o BSH, acabando por se tornarem documentos orientadores das políticas, sem muitas articulações entre as propostas que

\footnotetext{
9 Jéssyka Ribeiro (2014) expressa que o debate sobre as opressões de gênero/sexualidade é recente nas políticas públicas, demandando aprofundamento teórico-político crítico, uma vez que no contexto social do sistema capitalista, as relações sociais vigentes se encontram eivadas de conservadorismo, onde se reproduz diversas formas de machismo, a homo-lesbo-transfobia e tantas outras formas de preconceito e discriminação na vida social.
} 
intencionalmente foram criadas para serem incorporadas por essas políticas. Em contrapartida, avanços surgiram a partir das propostas da Conferência, criando o Plano Nacional de Promoção e cidadania e Direitos Humanos de LGBT (PNCDH-LGBT) em 2009. O documento do PNCDH-LGBT apresenta 51 diretrizes e dois eixos estratégicos com 180 ações, tendo por objetivo principal "[...] orientar a construção de políticas públicas de inclusão social e de combate às desigualdades para a população LGBT, primando pela intersetorialidade e transversalidade na proposição e implementação dessas políticas" (BRASIL, 2009, p.10). No que se refere à Política de Assistência Social, no interior do PNCDH-LGBT:

\begin{abstract}
No âmbito da assistência social, o Plano Nacional LGBT propõe a 'ampliação dos conceitos de família, de modo a contemplar os arranjos familiares LGBT' e também uma perspectiva de intersecção que possa 'assegurar a inclusão do recorte de orientação sexual e identidade de gênero, observando a questão étnico-racial, nos programas sociais do Governo Federal'. Outras ações concentram-se no combate à homofobia em órgãos municipais, estaduais e federais de assistência social, e ainda, em questões relacionadas à população carcerária LGBT (MELLO et al., 2013, p. 140).
\end{abstract}

Na PNAS, destaca-se a presença da expressão "[...] identidades estigmatizadas em termos étnico, cultural e sexual" na caracterização de vulnerabilidades dos/as usuários/as (CONSELHO NACIONAL DE COMBATE À DISCRIMINAÇÃO, 2004, p. 33). A mesma também aponta no subtítulo "Família e Indivíduos" 10 que o conceito de família passa por transformações, fazendo menção às mulheres que chefiam núcleos familiares, sem incluir, porém, famílias formadas por casais homossexuais, com ou sem filhos, biológicos ou adotivos. Excluem-se, além disso, famílias monoparentais, nas quais a/o mãe/pai é travesti, transexual, gay ou lésbica. (MELO et al., 2013). Ainda sobre o conceito de família e a inclusão de LGBT no mesmo, o PNCDH-LGBT traz apenas seis ações na esfera do Ministério do Desenvolvimento Social (MDS). A primeira delas se refere a "Reconhecer novos arranjos familiares, tais como as uniões homoparentais e os pares homoafetivos, para fins de aplicação da Política Nacional de Assistência Social", o que pode ser possível Projeto de Lei $\mathrm{n}^{\circ}$ 3077/2008, de autoria do Poder Executivo, que altera a Lei $\mathrm{n}^{\circ}$ 8.742, de 7 de dezembro de 1993, que dispõe sobre a organização da Assistência Social. Contudo, esta alteração ainda não foi realizada, sendo pouco provável que ainda venha a acontecer, levando-se em consideração o histórico do país no que se refere à efetividade de direitos de LGBTs. Exemplo disso é a PLC 122/2006 que há mais de dez anos vem sendo barrada pela bancada conservadora parlamentar. Ainda sobre as ações no âmbito do MDS,

Não é demais lembrar que este debate na esfera do Poder Legislativo não se resume ao projeto de lei em questão, o qual, por sua vez, não apresenta uma caracterização de família explícita o suficiente para contemplar os casais formados por pessoas do mesmo sexo, com ou sem filhos. Ainda no âmbito do MDS, o Relatório faz referência às ações 'Criar um programa de bolsas de estudo que incentive a qualificação ou educação profissional de Travestis e Transexuais em diversas áreas' e 'Garantir apoio psicossocial à população LGBT idosa' (MELLO et al., 2013, p. 142).

\footnotetext{
${ }^{10}$ A matricialidade sociofamiliar é um dos eixos estruturantes da PNAS. Berenice Rojas Couto (2015) afirma que é necessário fugir do pragmatismo que coloca um modelo de família ideal, pois deve-se levar em consideração as condições de vida de luta e de resistência do indivíduo e da população, para que se possa ofertar um serviço de qualidade conectado com as necessidades reais do/a usuário/a.
} 
Apesar do relatório colocar essas ações a serem realizadas, as mesmas não foram implementadas ou se quer planejadas a sua execução. Um dos motivos decorre da não alteração na redação da PNAS que incorpore a população LGBT em sua demanda (de forma explícita e com ações destinadas para os/as mesmos/as, posto que podem se enquadrar diante do termo vulnerabilidade social), outro fator se deve à falta de capacitação dos/as profissionais que fazem a política, bem como o não planejamento de ações para LGBT's de forma continuada. Não obstante, é possível identificar ações pontuais de inserção da população LGBT na Assistência Social a partir da implantação dos CREAS, cuja demanda foi aprovada como proposta na I Conferência Nacional LGBT. Em relação ao atendimento de LGBTs, com ações apenas pontuais, faz-se necessária uma reflexão, pois na PNAS:

Constitui o público usuário da política de Assistência Social, cidadãos e grupos que se encontram em situações de vulnerabilidade e riscos, tais como: famílias e indivíduos com perda ou fragilidade de vínculos de afetividade, pertencimento e sociabilidade; ciclos de vida; identidades estigmatizadas em termos étnico, cultural e sexual; desvantagem pessoal resultante de deficiências; exclusão pela pobreza e, ou, no acesso às demais políticas públicas; uso de substâncias psicoativas; diferentes formas de violência advinda do núcleo familiar, grupos e indivíduos; inserção precária ou não inserção no mercado de trabalho formal e informal; estratégias e alternativas diferenciadas de sobrevivência que podem representar risco pessoal e social (BRASIL, 2004, p. 27).

Logo, mesmo que os/as LGBTs não sejam mencionadas no documento da PNAS os/as mesmos/as são público da política, uma vez que se encontram em vulnerabilidade social devido violações de direitos ocasionadas pelo preconceito e pela estigmatização na sociabilidade heteronormativa ${ }^{11}$. Ressalta-se que apesar dos/as mesmos/as serem público de modo geral, a luta é para que estes/as sejam compreendidos/as em suas particularidades. É preciso entender que os/as LGBTs sofrem violações de direitos não apenas por fatores socioeconômicos, mas também por fatores culturais e morais, onde se pregam discursos de ódio aos/às mesmos/as.

Mota et al. (2010), discorre que as categorias de vulnerabilidade e risco social, podem se configurar como indicadores de "exclusão". Isto se deve ao fato de que o público alvo da PNAS é vasto e apresenta de maneira tão diversificada um leque de situações, podendo chegar até a comprometer o processo de normatização dos serviços prestados.

Em 2011 é realizada a II Conferência Nacional de Políticas Públicas e Direitos Humanos de LGBT. Esta teve por principal objetivo discutir o andamento das políticas públicas para LGBTs e os marcos legislativos para os/as mesmo/as até então. No que concerne à Política de Assistência Social foram aprovadas cinco diretrizes, uma delas diz respeito à introdução de novos arranjos familiares no Cadastro Único (CADÚNICO) da Assistência Social, com a criação dos campos: orientação sexual, identidade de gênero e o nome social para que a

\footnotetext{
${ }^{11}$ Por heteronormatividade, entende-se a reprodução de práticas e códigos heterossexuais, sustentada pelo casamento monogâmico, amor romântico, fidelidade conjugal, constituição de família (esquema pai-mãefilho(a)(s)). Na esteira das implicações da aludida palavra, tem-se o heterossexismo compulsório. Esse último é entendido como o imperativo inquestionado e inquestionável por parte de todos os membros da sociedade com o intuito de reforçar ou dar legitimidade às práticas heterossexuais (FOSTER, 2001, p. 19 apud MIRANDA, 2010, p. 84).
} 
população LGBT tenha acesso aos programas que utilizam os dados do CADÚnico como base, porém, cabe destacar que tais modificações não foram incorporadas aos cotidianos dos equipamentos do SUAS exemplo: o CREAS. Outra diretriz trata-se de garantir o reconhecimento e a efetivação das demandas relacionadas à orientação sexual e à identidades de gênero com recortes étnico-raciais, geracionais, referentes às pessoas em situação de rua, às pessoas com deficiência, às pessoas com HIV/AIDS e aos povos e comunidades tradicionais no processo de concessão do Benefício de Prestação Continuada (BPC). Outra diretriz a se destacar é a que visa implantar e efetivar a Política Nacional de Sensibilização e Formação Continuada dos/as Trabalhadores/as do SUAS das esferas Municipal, Estadual e Federal para inclusão e atendimento à população LGBT, essa é pouco realizada nas esferas federativas, e quando realizadas são de forma superficial, precária, e pontual ( sem continuidade).

Ademais, a III Conferência Nacional de Políticas Públicas e Direitos Humanos de LGBT ocorreu em 2016 e tivera quatro eixos temáticos todos voltados para reunir propostas que favorecessem o combate à violência contra LGBTs. Também discutiu sobre 0 desenvolvimento de políticas públicas para os/as LGBTs, e sobre a criminalização da homofobia ${ }^{12}$. No caso da Política de Assistência Social, verifica-se uma repetição de aprovação de diretrizes já aprovadas na conferência anterior.

Tais diretrizes já haviam sido aprovadas na II Conferência, mas não tiveram êxito em sua execução durante a pausa de uma conferência para a outra. Tal fato decorre da influência do conservadorismo, do fundamentalismo religioso, e do machismo nas decisões políticas, corroborando com uma sociedade conservadora, cujas ações estão pautadas na heteronormatividade e cisgeneridade. Outro ponto muito debatido na última conferência foi em relação ao Disque Direitos Humanos - Disque 100. Averiguou-se a necessidade de otimizá-lo a fim de criar protocolos para apurações e monitoramento e avaliação permanente de fluxo, com a divulgação de outras formas de denúncias por parte de conselhos e delegacias. Salienta-se que o disque 100 é uma das principais ferramentas de luta no que diz respeito à violência contra LGBTs. É por meio deste instrumento que a maioria dos casos de violação de direitos da pessoa LGBT chega aos CREAS, além de auxiliar com dados nos relatórios de violência homofóbica. Ademais, foi explicitado a urgência em "Fortalecer a divulgação da rede sócio assistencial e criar mecanismos de acolhimento e acompanhamento específico para as vítimas de violação dos direitos humanos LGBT e povos de terreiro" (BRASIL, 2016, p. 34).

A $11^{\text {a }}$ Conferência Nacional de Assistência social que ocorreu em 2017, pouco trata sobre a população LGBT, deixando suas ações restritas na participação e controle do SUAS, e na ampliação de recursos para cofinanciamento de todos os serviços na modalidade custeio e instituir o repasse financeiro para investir em bens de capital, devendo haver acréscimos nos repasses aos municípios com territórios dispersos e isolados, fator amazônico, comunidades e povos tradicionais, assentamentos rurais e regiões de fronteira internacional, considerando as diversidades e especificidades do público LGBT, imigrantes, população em situação de rua, juventude e pessoas com deficiência (BRASIL, 2017).

\footnotetext{
${ }^{12}$ Aqui se utilizará o termo homofobia ao invés de homo-lesbo-bi-transfobia devido ser o termo adotado pelo relatório da III Conferência Nacional de Políticas Públicas e Direitos Humanos de LGBT.
} 
Conclui-se, que apesar da inserção do debate sobre as opressões de gênero começarem a se fazerem presentes no contexto societário, com propostas de programas e ações a serem efetivados, infelizmente não se obteve rebatimentos significativos nas políticas sociais, sobretudo na PNAS.

\section{CONSIDERAÇÕES FINAIS}

Este artigo não pretende se colocar como chave para a superação da expressão da questão social aqui trabalhada, mas visa contribuir para o debate sobre a população LGBT e o atendimento ofertado pela Política de Assistência Social a este público na contemporaneidade. Esta população sofre com diversos tipos de discriminações e opressões em decorrência da sua identidade de gênero e orientação sexual, o que é reflexo das relações de gênero, implantadas na sociedade através da hierarquização dos sexos, e do modelo padrão heteronormativo.

É importante frisar que a violência contra LGBTs é algo histórico, resultante de normativas reguladoras, que impõe um modelo padrão, no qual os/as sujeitos/as devem cumprir, para não se tornar o que Butler (2013) chama de seres “[...] abjetos [...]" (BUTLER, 2013, p. 191) e "[...] inteligíveis [...]" (BUTLER, 2013, p. 39). Ainda é válido destacar que tais normativas de gênero, adentram o campo das políticas públicas, uma vez que estas são influenciadas pelos discursos do patriarcado, ocasionando, assim, em violências de direitos cotidianas (devido ao não reconhecimento de LGBTs enquanto sujeitos nas ações das políticas) e por vezes institucionais (ocasionadas por discriminação e preconceito).

Ademais, a ofensiva neoliberal acaba por fortalecer uma fragmentação desqualificada do atendimento às necessidades dessa população, recortando a questão social em questões sociais ${ }^{13}$ por via de políticas públicas paliativas e assistencialistas. Assim, a Política de Assistência Social se configura como mecanismo de consolidação de direitos sociais. No entanto, no que tange à população LGBT, observam-se impasses na garantia de seus direitos, uma vez que na redação da própria PNAS não se encontram os termos identidade de gênero e orientação sexual, e quando a mesma se refere a gênero é apenas em relação à mulher biológica, além de não incorporar famílias formadas por LGBTs na categoria família e indivíduos.

Outrossim, a atual conjuntura brasileira não dá espaço para a mudança de tais paradigmas na PNAS, uma vez que com o Golpe de Estado Parlamentar em 2016, intitulado pela direita conservadora enquanto impeachment, ocasionou no afastamento da presidente Dilma Rousseff, colocando à presidência Michel Temer. Após o golpe, reduziu-se o número de ministérios brasileiros de 32 para 23, com o objetivo de reduzir gastos do Poder Executivo. Entre as mudanças está a fusão do Ministério do Desenvolvimento Social e Combate à Fome (MDS), com o Ministério do Desenvolvimento Agrário. Outro fator que afeta diretamente a Política de Assistência Social é a Proposta de Emenda Constitucional (PEC) de $n^{\circ}$ 241/2016, que institui um novo regime Fiscal para a União, com vigência de 20 anos a partir de 2017, colocando uma limitação anual das despesas da União, ou seja, apenas

\footnotetext{
${ }^{13} \mathrm{~A}$ ofensiva neoliberal traz um recorte da questão social em questões sociais, colocando-as, assim, como questões descontextualizadas da ordem do capital, resgatando a ideia de culpabilização do indivíduo e desresponsabilização do Estado (BEHRING, 2006).
} 
poderá ter gasto o valor do ano anterior, corrigido pelo Índice Nacional de Preços ao Consumidor (IPCA). Esta PEC coloca verdadeiramente em ação o plano neoliberal frente às políticas sociais. Nesse sentido, a Política de Assistência Social, cujo sistema (SUAS) que é ainda recente, obtendo apenas 11 anos de execução sofrerá danos, pois seu orçamento para desenvolvimento das ações será limitado. Vale ressaltar que a PNAS não tem orçamento próprio o que agravará a situação.

No que concerne à política de Assistência Social voltada para os/as LGBTs, nesse contexto, os/as mesmos/as não são reconhecidos/as em suas particularidades no interior desta, o que ocasiona em ações frágeis, quando não inexistentes. Aprimorar estas ações, ou mesmo incluí-las nos planos anuais da PNAS demandaria de não só um planejamento orçamentário no qual a política está sendo gravemente ferida, mas também da incorporação de fato de um Estado laico, que reconheça que as ações deste não devem ser contaminadas pela ideologia conservadora e/ou religiosa de seus representantes quando se trata da efetivação de direitos dos/as cidadãos.

Logo, percebe-se que muito ainda se tem a discutir sobre esta temática, para que se possa ter não só a desconstrução de uma sexualidade padrão, mas também para que os diretos dos/as LGBTs não sejam violados por aqueles/as que deveriam contribuir na sua defesa. É através de tais discussões que aos poucos se haverá a inclusão de fato da população LGBT no contexto societário, enquanto sujeitos/as de direitos, sobretudo no ínterim da PNAS.

\section{REFERÊNCIAS}

ANJOS, Gabriele. Identidade sexual e identidade de gênero: subversões e permanências. Sociologias, Porto Alegre, ano 2, n. 4, p.274-305, jul./dez. 2000.

BAZZA, C. M.; CARVALHO, F. X. de. A política de assistência social na contemporaneidade: considerações sobre a realidade brasileira. Revista UNINGÁ Review, v. 15,n. 1, p. 29-34, jul./set. 2013.

BEHRING, Elaine R. Expressões política da crise as novas configurações do Estado e da sociedade civil. In: BEHRING, Elaine R. (Org.). Serviço Social: direitos sociais e competências profissionais. Brasília (DF): Conselho Federal de Serviço Social; Associação Brasileira de Ensino e Pesquisa em Serviço Social, 2009. v. 1, p. 69-86.

BEHRING, Elaine R. Política Social no Brasil Contemporâneo: entre a inovação e o conservadorismo. In: BEHRING, Elaine R. (Org.). Política Social: fundamentos e história. São Paulo: Cortez, 2006. v. 2. p. 147-191.

BRASIL. Constituição da República Federativa do Brasil. Diário Oficial da República Federativa do Brasil, Brasília (DF), 2012.

BRASIL. Presidência da República. Lei n. 8.742, de 07 de dezembro de 1993. Lei Orgânica da Assistência Social (LOAS). Dispõe sobre a organização da assistência social e dá outras providências. Brasília, 1993. Diário Oficial da República Federativa do Brasil, Brasília (DF), 
8 dez. 1993. Disponível em: <http://www.planalto.gov.br/ccivil_03/leis/l8742.htm>. Acesso em: 23 maio 2014.

BRASIL. Ministério do Desenvolvimento Social. Resolução $n^{\circ}$ 21, de 18 de dezembro de 2017. Dispõe sobre as deliberações da $11^{\text {a }}$ Conferência de Assistência Social. Diário Oficial da União, Brasília (DF), Ano 154, n. 242, 19 dez. 2017. Seção I. Disponível em: <http://www.mds.gov.br/cnas/legislacao/resolucoes/arquivos-2017/cnas-2017-021-18-122017b.pdf/download.>. Acesso em: 18 out. 2018.

BRASIL. Ministério do Desenvolvimento Social e Combate à Fome. Norma Operacional Básica: NOB/SUAS. Brasília (DF), 2012.

BRASIL. Ministério do Desenvolvimento Social e Combate à Fome. Norma Operacional Básica de Recursos Humanos do SUAS. Brasília (DF), 2006.

BRASIL. Ministério do Desenvolvimento Social e Combate à Fome. Norma Operacional Básica: NOB/SUAS: construindo as bases para a implantação do Sistema Único de Assistência Social. Brasília (DF), 2005.

BRASIL. Ministério do Desenvolvimento Social e Combate à Fome. Política Nacional de Assistência Social. Brasília (DF), 2004.

BUTLER. Judith. Problemas de gênero: feminismo e subversão da identidade. Rio de Janeiro: Civilização Brasileira, 2013.

CAMURÇA, Sílvia; GOUVEIA, Taciana. O que é gênero. 4. ed. Recife: SOS CORPO Instituto Feminista para a Democracia, 2004.

CONSELHO NACIONAL DE ASSISTÊNCIA SOCIAL. Nota do CNAS contrária a PEC 241/2016. Brasilía (DF), 2016. Disponível em:

$<$ https://conferencianacional.files.wordpress.com/2016/09/nota-do-cnas-pec-241-pc3b3splenc3a1ria.pdf $>$. Acesso em: 1 out. 2016.

CONSELHO NACIONAL DE COMBATE À DISCRIMINAÇÃO (Brasil). Brasil sem Homofobia: Programa de combate à violência e à discriminação contra GLTB e promoção da cidadania homossexual. Brasília (DF): Ministério da Saúde, 2004. Disponível em:

<http://bvsms.saude.gov.br/bvs/publicacoes/brasil_sem_homofobia.pdf >. Acesso em: 17 fev. 2013.

COUTO, Berenice R.. Assistência Social: direito social ou benesse?. Revista Serviço social e Sociedade, São Paulo, n. 124, p. 665-677, out./dez. 2015.

FACCHINI, Regina. Sopa de letrinhas?: Movimento homossexual e produção de identidades coletivas nos anos 90. Rio de Janeiro: Garamond, 2005. 
FACCHINI, Regina; FRANÇA, Isadora Lins. 2009. "De cores e matizes: sujeitos, conexões e desafios no Movimento LGBT brasileiro". Sexualidad, Salud y Sociedad: Revista Latinoamericana, n.3, p. 54-81.

FOUCAULT, M. História da sexualidade; a vontade de saber. Rio de Janeiro: Graal, 1997.

FOUCAULT, Michel. História da sexualidade I: a vontade de saber. 18. ed. Rio de janeiro: Graal, 1988.

GRUPO GAY DA BAHIA. Mortes Violentas de LGBT no Brasil: relatório 2017. Disponível em: <https://homofobiamata.files.wordpress.com/2017/12/relatorio-2081.pdf $>$. Acesso em: 14 out. 2018

LEITE JUNIOR, Jorge. Transitar para onde? Monstuosidade, (des)patologização, (in)segurança social e identidades transgêneras. Revista Estudos Feministas, Florianópolis, v. 20, n. 2, p.559-568, maio/ago. 2012.

MELLO, Luiz; et al. Políticas Públicas de Trabalho, Assistência social e Previdência Social para a Populção LGBT no Brasil: Sobre os Desejos, Realizações e Impasses. Revista de Ciências Sociais, Fortaleza, v. 44, n. 1, p. 132-160, jan./jun. 2013.

MISKOLCI, Richard. A gramática do armário: notas sobre segredos e mentiras em relações homoeróticas masculinas mediadas digitalmente. International Congress of LASA, 30, 2012, San Francisco, Anais..., LASA 2012 Congress Paper Archive. Pittsburgh: LASA, 2012. v. 1. p. 1-25.

MOTA, Ana E.; MARANHÃO, Cezar Henrique; SITCOVSKY, Marcelo. As tendências da política de Assistência Social. O Suas e a formação profissional. In: MOTA, Ana Elizabete (Org.). $O$ mito da assistência social: Ensaios sobre Estado, Política e Sociedade. 4. ed. São Paulo: Cortez, 2010.

PRECIADO, Beatriz. Multidões queer: notas para uma política dos "anormais". Estudos Feministas, Florianópolis, v. 19 (1):312, p. 11-20, jan./abr. 2011.

RIBEIRO, Jéssyka K. A. Uma análise do atendimento a populações LGBT no âmbito do CREAS: reflexões sobre o atendimento da população LGBT no CREAS. In: CONGRESSO BRASILEIRO DE ASSISTENTES SOCIAIS (CBAS), 14., Águas de Lindóia, 2014. Anais... Águas de Lindóia, 2014.

SADEMBERG, Cecilia M. B.; MACÊDO, Márcia S. Relações de gênero: uma breve introdução ao tema. In: COSTA, Ana Alice Alcantara; TEIXEIRA, Alexnaldo; VANIN, Iole Macedo (Orgs.). Ensino e Gênero: Perspectivas Transversais. Salvador: UFBA - NEIM, 2011. p.33- 48 .

SCOTT, J. W. "Gênero: uma categoria útil para a análise histórica." Traduzido pela SOS: Corpo e Cidadania. Recife, 1990. 
TONELI, MJF. Sexualidade, gênero e gerações: continuando o debate. In: JACÓ-VILELA, A. M.; SATO, L. (Orgs.). Diálogos em psicologia social. Rio de Janeiro: Centro Edelstein de Pesquisas Sociais, 2012. p. 147-167. ISBN: 978-85-7982-060-1. 